\title{
EDUCATIONAL PROGRAMS AND RECIDIVISM IN OKLAHOMA: ANOTHER LOOK
}

\author{
DENNIS R. BREWSTER \\ SUSAN F. SHARP \\ University of Oklahoma
}

\begin{abstract}
Prior research suggests that educational programs are one of the most effective tools in reducing recidivism rates. In this study, however, the authors found that some educational programs administered in Oklahoma may not have an ameliorative effect on criminality. Specifically, they found that completion of a general equivalency diploma program was strongly associated with longer survival times outside of prison, particularly for women. However, for both men and women, completion of vocationaltechnical training while incarcerated was linked to shorter survival times. This indicates the need to evaluate the types of training offered in prisons.
\end{abstract}

Incarceration rates have soared during the past two decades of the 20th century. From 1990 to 1998, the number of prisoners in the U.S. increased from 292 per 100,000 residents to 461 per 100,000 residents (Beck \& Mumola, 1998). With increasing numbers of the American population incarcerated, researchers and corrections officials alike are exploring ways to reduce the likelihood of offenders returning to prison once released. Education has been viewed as one effective means of reducing recidivism (Council of State Governments, 1998; Gerber \& Fritsch, 1995; Harr, 1999; Tracy, Smith, \& Steurer, 1998). Indeed, the 1995 International Correctional Education Association Conference focused on the value of prison education as a tool to reduce recidivism (Duguid, Hawkey, \& Pawson, 1996). This article examines the relationship between education and recidivism in Oklahoma. Our findings are disturbing, suggesting that education may not always be linked to reduced recidivism.

\section{RECIDIVISM}

One problem with the literature on correlates of recidivism is the inconsistency in the measurement of recidivism (Jancic, 1998). For example, a report

THE PRISON JOURNAL, Vol. 82 No. 3, September 2002 314-334

(C) 2002 Sage Publications

314

Downloaded from tpj.sagepub.com at UNIV OF OKLAHOMA on January 20, 2016 
on federal releasees used rearrest or parole revocation as the measure of recidivism (Harer, 1995). The use of reincarceration as a recidivism measure appears to be normative, however. A recent meta-analysis of 33 studies reports four different recidivism measures: reincarceration, arrest after release, new conviction, and parole revocation. In two-thirds of the cases, recidivism was measure by reincarceration (D. B. Wilson, Gallagher, \& MacKenzie, 2000). Of course, the measure of recidivism chosen is affected by the focus of the study. If one is interested in evidence of changed behaviors, rearrest might be the preferred measure. However, if the focus is on program effectiveness in keeping individuals out of the correctional system, reincarceration would be an effective measure (Stevens \& Ward, 1997). In this study, we have chosen reincarceration as our measure of recidivism. Our interest is the degree to which educational programming in Oklahoma increases the time offenders remain out of the system; thus, reincarceration seems the most reasonable measure.

\section{CORRECTIONAL EDUCATION AND RECIDIVISM}

\section{GENERAL EQUIVALENCY DIPLOMA (GED), \\ VOCATIONAL-TECHNICAL, AND RECIDIVISM}

High incarceration rates and restricted budgets are leading policy makers to assess the effectiveness of existing and proposed programs (Duguid et al., 1996; Jancic, 1998; McCollum, 1977). The research findings, however, are

somewhat mixed. On one hand, we find evidence that correctional education is effective in reducing recidivism rates. For example, some research suggests that exposure to educational programs is strongly linked to lower rates of recidivism (Gerber \& Fritsch, 1995; Harer, 1995; Jancic, 1998; Tracy et al., 1998). Similarly, recidivism for driving-while-impaired offenders was $24 \%$ among non-high school graduates but only $13 \%$ for those receiving additional educational programming (Kernodle, Joyce, \& Farmer, 1995). On the other hand, there is some evidence that some educational programs are not as effective as desired in reducing recidivism. A 1974 study has left a telling legacy for correctional education and other rehabilitation programs. The author asserted that in terms of reducing recidivism, "nothing works" (Martinson, 1974). Although he later qualified his results (Martinson, 1979), additional studies have suggested that his conclusions have some validity (Chown \& Davis, 1986; Davis, 1985; Piehl, 1998). Other earlier research has suggested that only extensive education was linked to reducing recidivism (Schnur, 1948). Similarly, a 1966 study found that longer courses created 
more investment on the part of the students, leading to lower rates of recidivism (Glaser, 1966). These findings have led to programs that require offenders' active participation in their own rehabilitation. In this model, prisoners are expected to demonstrate behavioral changes (Allison, 1993).

Other researchers have contested the "nothing works" doctrine. For example, Flanagan (1994) concluded that the data used by Martinson (1974) did not support his conclusions. Others have examined the existing literature and suggested that overall, the data suggest education does reduce recidivism (Anderson, Schumacher, \& Anderson, 1991; Jancic, 1998; Schumacher, Anderson, \& Anderson, 1990; Tracy et al., 1998). This issue is important because of policy implications. In some states, prisons have faced the prospect of elimination of educational programs. During the 1990s, two attempts were made in Maryland alone to reduce or eliminate correctional education programs (Tracy et al., 1998). Thus, it is important to closely examine correctional education programming to determine what does work and why.

The data suggest that adult basic education and high school equivalency programs are needed (Morison, 1992). For example, recidivism rates were found to be highest among federal prison releasees with less than high school educations (Harer, 1994, 1995; Jancic, 1998). An analysis of 60 different studies suggested that for those lacking a high school diploma, education while incarcerated was linked to lower rates of recidivism (Flanagan, 1994). One study of prisoners released in 1983 reported that those with less than high school educations had the highest recidivism rates (Beck \& Shipley, 1989). Similarly, parole success has been linked to educational level (Sims \& Jones, 1997).

However, the research has been less conclusive about the benefits of vocational and postsecondary educational programs for offenders. One study found that vocational programs were effective in reducing recidivism among youth offenders, whereas academic programs were not effective (P. R. Wilson, 1994). On the other hand, two studies of correlates of recidivism among Oklahoma offenders found that those receiving vocational training returned to prison at a faster rate than those who did not receive vocational training (Chown \& Davis, 1986; Davis, 1985). Overall, the preponderance of the research does suggest that vocational rehabilitation and, to a lesser extent, academic educational programs do reduce the likelihood of recidivism (Anderson et al., 1991; Batiuk, Moke, \& Roundtree, 1997; Harley, 1996; Ryan \& Mauldin, 1992; Schumacher et al., 1990; Stevens \& Ward, 1997; Tracy et al., 1998). The conflicting empirical evidence suggests the need for further study.

Providing successful correctional education is not a simple task. Instead, we need to assess the utility of different programs, to assess "what works for 
whom, when, why and under what circumstances" (Duguid et al., 1996, p. 74; see also Lab \& Whitehead, 1997). Simply providing "educational experiences" may have little if any effect on the postrelease lives of offenders. We must also explore the context and mechanisms of educational programs in the prisons (Duguid et al., 1996). Furthermore, we need to take into account preincarceration risk level as well as gender and drug use in future assessments of programs (Andrews et al., 1990).

\section{GENDER AND CORRECTIONAL EDUCATION}

Gender may play an important role in the efficacy of correctional educational programs. Although women comprise a small percentage of prisoners, in the past 10 years, the incarceration rate of women has increased far more rapidly than that of men. However, vocational programs have primarily focused on supporting stereotypical female roles (Carlson, 1995; Morash, Haarr, \& Rucker, 1994; Schram, 1998; Weisheit, 1985). In some cases, the programs appear to be geared more to maintenance of the prison than to preparation of offenders for reentry into society (Winifred, 1996). Thus, many of the vocational programs offered in women's prisons have been ineffective in preventing recidivism. In Oklahoma, the state with the highest female incarceration rate, a recent study indicated that programs for female offenders are not equivalent to those for male offenders. The task force assigned to assess this issue has made recommendations for additional vocational programs for women (Oklahoma Department of Corrections, 1999). To date, this has had little effect. Currently, vocational training for female offenders is limited primarily to janitorial services, horticultural services, and computer training (Oklahoma Department of Career and Technology Education, 2001). Another Oklahoma study found that completion of a vocational-technical program while incarcerated was associated with shorter survival times for female offenders. The author concluded that lack of marketable skills and unrealistic expectations may have contributed to this finding (Brewster, 1999). However, the Brewster study and the Oklahoma Department of Corrections study have focused on problems in educational programming for women. Prior research has also indicated that correctional education for male inmates in Oklahoma may be problematic (Chown \& Davis, 1986; Davis, 1985). Therefore, examination of the relationship between correctional education and postrelease survival for both male and female offenders is needed. Vocational programming for men includes horticulture, computer training, and automotive repair. In addition, apprenticeship programs are offered in meat cutting, commercial food preparation, and cabinet building (Oklahoma 
Department of Career and Technology Education, 2001). Thus, there is a wider range of educational programming available for male inmates.

In Oklahoma, two factors related to participation in vocational-technical programs may be salient. First, inmates are assessed for vocational training needs (Oklahoma Department of Career and Technology Education, 2001). When vocational training is recommended, participation by the inmates is "voluntary." According to personnel in the Vocational Rehabilitation Office of the state, failure to participate in a recommended program is linked to reduction in privileges. Thus, inmates may "volunteer" to engage in vocational training but may not be motivated to benefit from the training. Some inmates may select into the program simply to avoid sanctions. Second, Oklahoma has a low completion rate for vocational training. This may be due to the small number of slots available, or it may be due to frequent transfers from one facility to another.

\section{STATEMENT OF THE PROBLEM}

In this study, we examine the association between survival time and both high school equivalency or GED programs and vocational-technical programs. In our first hypothesis, we hypothesize that completion of GED programs will be linked to longer survival time-in other words, to longer postrelease time without reincarceration. On the other hand, the literature suggests that vocational programs have less clear-cut effects. In particular, gender appears to be a factor in the efficacy of vocational programs. Thus, Hypothesis 2 suggests that vocational-technical programs will have different effects for male and female offenders. We anticipate that vocational-technical programs may be effective in increasing survival time for male offenders but not for female offenders. To test these hypotheses, we will examine the records of all offenders released from the Oklahoma Department of Corrections from January 1991 through December 1994. These records provide recidivism data through July 1997.

\section{METHOD}

Data used in this study were provided by the Oklahoma Department of Corrections (see Holley \& Brewster, 1997). The complete data set contained 21,268 cases representing all offenders released from the Oklahoma Department of Corrections between January 1, 1991, and December 31, 1994. Information on recidivism was available through July 1997. For the purposes of this study, analyses were limited to those offenders released from 
maximum-security, medium-security, minimum-security, or community correctional institutions, resulting in a final population size of 11,813 cases. To test our first hypothesis, we limited analyses to those offenders who entered the custody of the Oklahoma Department of Corrections without a high school diploma or a GED $(N=5,752)$. Analyses for the second hypothesis were tested using all offenders in the population $(N=11,813) .{ }^{1}$

\section{DESCRIPTION OF VARIABLES}

The dependent variable was the number of months that offenders stayed out of the Oklahoma Department of Corrections or the survival time (SURVIVAL). Because not all of the releasees had returned to the correctional setting, we set the cutoff date at July 1997, the date the data were received. Survival (in months) was computed for all offenders. Because some offenders were released as early as 1991, it was possible for some to have more than 60 months of survival. Using Cox's regression models, it is possible to use all of the offenders, including those who had reached the end of the study time as nonrecidivists, yet their survival in the future was undetermined. ${ }^{2}$

Independent variables for this study included a secondary education variable (GED), a vocational education variable (VO-TECH), and the sex of participants (SEX). The GED variable was coded 1 if participants completed the GED program while incarcerated and 0 if participants did not complete the program while incarcerated. The VO-TECH variable was coded 1 if participants completed a vocational education program while incarcerated and 0 if they had not. The independent variable SEX was coded 1 if participants were female and 0 if male.

Control variables were used to ensure demographic, offense, and release variables were held constant. The age of offenders (AGE) was an interval variable based on officially recorded age. The race of offenders (RACE) was a dummy variable with Black coded as 1 , whereas all other groups were coded as 0. Marital status (MARITAL STATUS) was a dummy variable coded 1 if unmarried (divorced or single) and 0 if married. ${ }^{3}$

Offense variables included offense type and sentence length. Recidivism has been linked to drug use. Although those convicted of drug sales and/or distribution were not necessarily users, both dealers and users have high recidivism rates (Anderson et al., 1991). Thus, possession of drugs (POSSESSION) was a dummy variable coded 1 if offenders were convicted of the offense of illegal possession of controlled substances and 0 for all other offenses. If offenders were convicted of illegal distribution of controlled substances, the distribution variable (DISTRIBUTION) was coded 1 . The omit- 
ted category in the analyses below was all other offenses. The length of sentence (SENTENCE LENGTH) was an interval variable measured in years.

Cox's regression was used. Survival analysis indicating survival (SURVIVAL) in months of offenders was censored by the recidivism (RECIDIVISM) measure. Recidivism was coded 1 if offenders had returned to the custody of the Oklahoma Department of Corrections by July 1997 and 0 if they had not returned. Because many of the offenders (almost $65.6 \%$ ) had not recidivated at the time the data were received, it was necessary to use the Cox regression survival method. All models controlled for the demographic characteristics of offenders. Population analyses were conducted on the data, thus eliminating many of the problems of sampling (Babbie, 1995; Henry, 1998).

\section{FINDINGS}

\section{DESCRIPTION OF POPULATION}

Distributions of the control, independent, and dependent variables are reported in Table 1. The data indicate that the population of offenders in Oklahoma is young, with the mean age (AGE) for the overall population 28.9 years and 27.8 years for the GED subpopulation.

The offender population in Oklahoma is somewhat different from the national population in terms of the gender composition of the population. Nationally, incarcerated women constitute slightly more than $5 \%$ of the incarcerated population. In Oklahoma, however, women account for more than $10 \%$ of those in prison (Snell \& Morton, 1994). This is reflected in the release population as well. Women account for $9.5 \%$ of the GED subpopulation and $10.0 \%$ of the total population.

Analyses support earlier findings that Blacks are heavily overrepresented (RACE) in the offender population in Oklahoma (Oklahoma Department of Corrections, 1998). Blacks account for $32.5 \%$ of the released offender population, with the remaining $67.5 \%$ composed of all other races. Among those in the GED subpopulation, $28.4 \%$ are Black and $71.6 \%$ are of other races. ${ }^{4}$ Table 1 also indicates that $52.7 \%$ of the population under study is single or divorced, with $47.3 \%$ married. In the GED subpopulation, $55 \%$ are single and $45 \%$ married (MARITAL STATUS).

Drug offenses account for $17.1 \%$ of the population and $16.4 \%$ of the GED subgroup. Incarceration for illegal possession constituted $5.9 \%$ of the GED subgroup and $6.5 \%$ of the total population. DISTRIBUTION accounted for $10.5 \%$ of the GED group and $10.6 \%$ of the total population. The mean sen- 
Brewster, Sharp / EDUCATIONAL PROGRAMS AND RECIDIVISM 321

TABLE 1: Frequency Distributions of Demographic, Control, and Independent Variables

\begin{tabular}{|c|c|c|}
\hline Variable & $\begin{array}{l}\text { GED Model } \\
(\mathrm{N}=5,752)\end{array}$ & $\begin{array}{l}\text { Vocational-Technical and } \\
\text { Overall Model }(\mathrm{N}=11,813)\end{array}$ \\
\hline Mean age (reported in years) & 27.8 & 28.9 \\
\hline \multicolumn{3}{|l|}{ Sex } \\
\hline Male & $\begin{array}{l}5,204 \\
\quad(90.5 \%)\end{array}$ & $\begin{array}{l}10,635 \\
(90.0 \%)\end{array}$ \\
\hline Female & $\begin{array}{l}548 \\
(9.5 \%)\end{array}$ & $\begin{array}{l}1,178 \\
(10.0 \%)\end{array}$ \\
\hline \multicolumn{3}{|l|}{ Race } \\
\hline Black & $\begin{array}{l}1,635 \\
(28.4 \%)\end{array}$ & $\begin{array}{l}3,846 \\
(32.5 \%)\end{array}$ \\
\hline Other & $\begin{array}{l}4,117 \\
\quad(71.6 \%)\end{array}$ & $\begin{array}{r}7,977 \\
(67.5 \%)\end{array}$ \\
\hline \multicolumn{3}{|l|}{ Marital status } \\
\hline Single & $\begin{array}{l}3,166 \\
\quad(55.0 \%)\end{array}$ & $\begin{array}{l}6,231 \\
\quad(47.3 \%)\end{array}$ \\
\hline \multicolumn{3}{|l|}{ Offense } \\
\hline Drug possession & $\begin{array}{l}338 \\
(5.9 \%)\end{array}$ & $\begin{array}{l}773 \\
(6.6 \%)\end{array}$ \\
\hline Drug distribution & $\begin{array}{l}606 \\
(10.5 \%)\end{array}$ & $\begin{array}{l}1,253 \\
(10.6 \%)\end{array}$ \\
\hline Other & $\begin{array}{l}4,808 \\
(83.6 \%)\end{array}$ & $\begin{array}{l}9,787 \\
(82.8 \%)\end{array}$ \\
\hline \multicolumn{2}{|l|}{ Mean sentence length } & 5.5 \\
\hline \multicolumn{3}{|l|}{ Recidivism } \\
\hline Yes & $\begin{array}{l}2,183 \\
\quad(38.0 \%)\end{array}$ & $\begin{array}{l}4,406 \\
(37.3 \%)\end{array}$ \\
\hline No & $\begin{array}{l}3,569 \\
(62.0 \%)\end{array}$ & $\begin{array}{l}7,407 \\
(62.7 \%)\end{array}$ \\
\hline \multicolumn{3}{|l|}{ GED completion } \\
\hline Yes & $\begin{array}{l}1,044 \\
(18.2 \%)\end{array}$ & - \\
\hline No & $\begin{array}{l}4,708 \\
\quad(81.8 \%)\end{array}$ & - \\
\hline \multicolumn{3}{|l|}{ Vocational-technical completion } \\
\hline Yes & - & $\begin{array}{l}805 \\
(6.8 \%)\end{array}$ \\
\hline No & - & $\begin{array}{l}11,008 \\
(93.2 \%)\end{array}$ \\
\hline
\end{tabular}

NOTE: GED = general equivalency diploma.

tence length (SENTENCE LENGTH) for those released from 1991 to 1994 was 5.5 years and 5.2 years for the GED subgroup. The variable RECIDIVISM indicates that $62.7 \%$ of the offenders released from 1991 to 
1994 had not recidivated by July 1997, with $62 \%$ of the GED subgroup not recidivating. ${ }^{5}$

The GED analyses were restricted to those offenders who entered custody without a GED or high school diploma. Of the 11,813 offenders released between the beginning of 1991 and the end of 1994, 5,752 entered the Department of Corrections without a high school education. Among these offenders, only 1,044 (18.2\%) completed a GED program while under the supervision of the Oklahoma Department of Corrections. Only 6.8 or 805 of the 11,813 offenders released between 1991 and 1994 completed a vocational education program while incarcerated.

\section{GED MODELS}

Results of the logistic regression for the GED model $(N=5,746)$ are found in Table 2. In Model 1, we introduced the demographic variables and offense variables. The Cox survival analysis indicates that age, race, and marital status were significantly associated with survival time. The variable age had a negative relationship to the dependent variable (SURVIVAL), indicating that the older the offenders, the more likely they were to have shorter survival time. When considering the effects of race on survival times, Blacks were more likely to have lower survival times. Furthermore, those who indicated they were single or divorced were more likely to survive longer than were those who were married.

Those convicted of drug possession (POSSESSION) were not significantly different from other offenders in the length of their survival without reincarceration. However, those convicted of drug distribution (DISTRIBUTION) had significantly longer survival times overall. Those offenders who were sentenced to longer sentences (SENTENCE LENGTH) were found to have slightly longer survival times than did those with shorter sentences. The $-2 \log$ likelihood for this model is 35,928.97.

In Model 2 of Table 2, we added the independent variable GED. The same relationships and significance were found for the control variables as in Model 1. The independent variable GED was positive and statistically significant $(b=0.313, p \leq .001)$, indicating that those who completed a GED program while in custody were more likely to have longer survival times. The -2 log likelihood for this model is 35,901.75. ${ }^{6}$

The sex of offenders (SEX) was added in Model 3 (see Table 2). The relationship was positive and statistically significant $(b=0.289, p \leq .001)$. This suggests that women were more likely to have longer survival times compared with men. The $-2 \log$ likelihood for this model is $35,887.51 .^{7}$ Figure 1 graphically depicts the effect of sex on survival times. 
TABLE 2: GED Models on Survival in Months (Cox regression coefficients, standardized errors in parentheses)

\begin{tabular}{|c|c|c|c|c|c|c|c|c|c|}
\hline \multirow[b]{2}{*}{ Variable } & \multicolumn{3}{|c|}{ Model 1} & \multicolumn{3}{|c|}{ Model 2} & \multicolumn{3}{|c|}{ Model 3} \\
\hline & \multicolumn{2}{|c|}{$\begin{array}{l}\text { Regression } \\
\text { Coefficient }\end{array}$} & $\begin{array}{l}\text { Odds } \\
\text { Ratio }\end{array}$ & \multicolumn{2}{|c|}{$\begin{array}{l}\text { Regression } \\
\text { Coefficient }\end{array}$} & $\begin{array}{l}\text { Odds } \\
\text { Ratio }\end{array}$ & \multicolumn{2}{|c|}{$\begin{array}{l}\text { Regression } \\
\text { Coefficient }\end{array}$} & $\begin{array}{l}\text { Odds } \\
\text { Ratio }\end{array}$ \\
\hline \multicolumn{10}{|c|}{ Demographic variables } \\
\hline Age & $0.036^{\star \star \star}$ & $(0.003)$ & 0.964 & $-0.038^{\star \star \star}$ & $(0.003)$ & 0.962 & $-0.038^{\star \star \star}$ & $(0.003)$ & 0.962 \\
\hline Race & $-0.505^{\star \star \star}$ & $(0.045)$ & 0.603 & $-0.471^{\star \star \star}$ & $(0.046)$ & 0.624 & $-0.490^{\star \star \star}$ & $(0.046)$ & 0.6013 \\
\hline Marital status & $0.268^{\star * *}$ & $(0.047)$ & 1.307 & $0.262^{\star \star \star}$ & $(0.047)$ & 1.300 & $0.284^{\star \star *}$ & $(0.048)$ & 1.329 \\
\hline \multicolumn{10}{|l|}{ Offense variables } \\
\hline Possession & -0.074 & $(0.086)$ & 0.929 & -0.072 & $(0.086)$ & 0.930 & -0.094 & $(0.087)$ & 0.910 \\
\hline Distribution & $0.324^{\star \star *}$ & $(0.077)$ & 1.383 & $0.304^{\star \star *}$ & $(0.077)$ & 1.355 & $0.289^{\star \star *}$ & $(0.077)$ & 1.335 \\
\hline Sentence length & $0.001^{*}$ & $(0.000)$ & 1.001 & $0.001^{*}$ & $(0.000)$ & 1.001 & $0.001^{*}$ & $(0.000)$ & 1.001 \\
\hline \multicolumn{10}{|c|}{ Independent variables } \\
\hline GED & \multirow{2}{*}{\multicolumn{2}{|c|}{ - }} & - & $0.313^{\star * \star}$ & $(0.062)$ & 1.368 & $0.314^{\star \star *}$ & $(0.062)$ & 1.369 \\
\hline Sex & & & - & \multicolumn{2}{|c|}{-10.001} & - & $0.289^{\star \star \star}$ & $(0.079)$ & 1.334 \\
\hline
\end{tabular}

NOTE: GED = general equivalency diploma.

${ }^{\star} p \leq .05 .{ }^{* *} p \leq .01 .{ }^{* * *} p \leq .001$. 


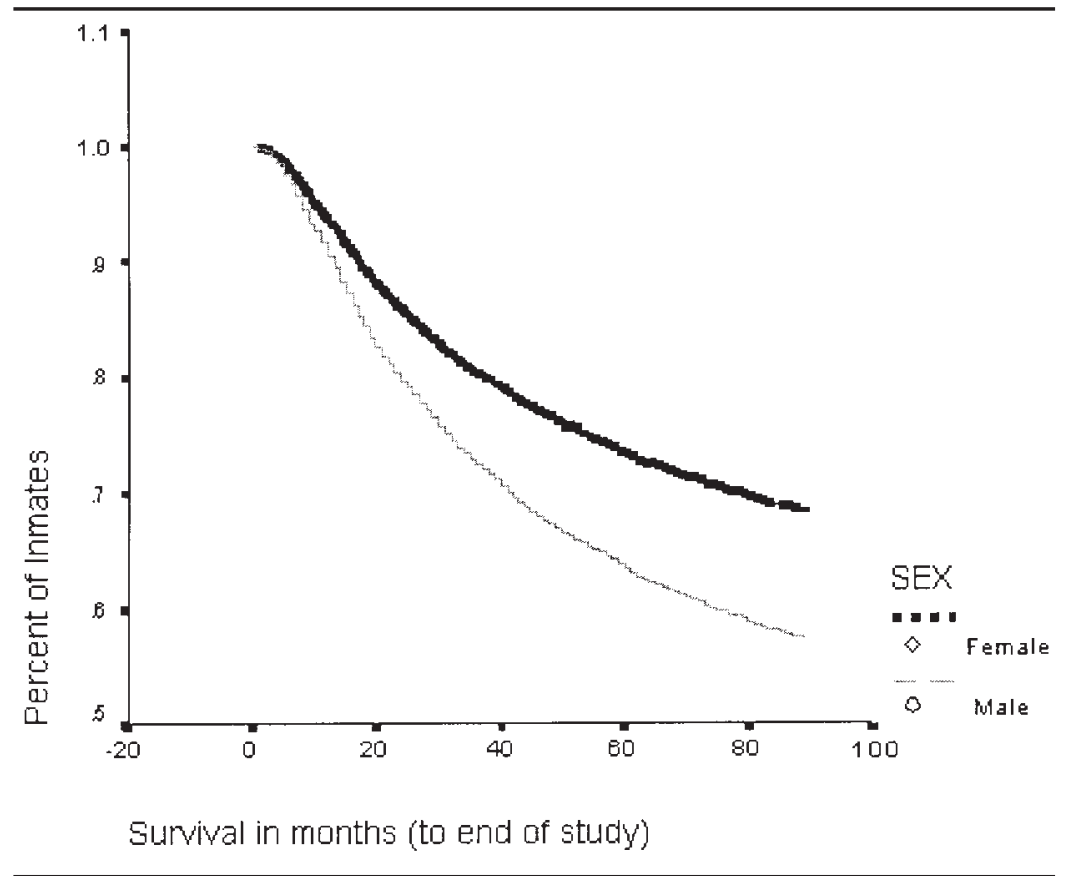

FIGURE 1: Survival in Months by Oklahoma Department Corrections (general equivalency diploma model)

\section{VO-TECH MODELS}

When analyzing the effects of the vocational education programs in Oklahoma $(N=11,813)$, we found that the control variables were statistically significant. Model 1 of Table 3 indicates that as in the GED analysis, as age increased, the likelihood of longer survival times decreased. RACE was also negatively associated with survival time, indicating that Blacks were more likely to recidivate sooner than were non-Blacks. As in the GED model, marital status (MARITAL STATUS) of offenders was statically significant and positive, suggesting that those who were single or divorced were more likely to have longer survival times as compared with those who were married.

Those convicted of drug distribution (DISTRIBUTION) were significantly more likely to have longer periods of survival than were other offenders, whereas drug possession (POSSESSION) was not related to survival time, as in the GED models. The length of sentence (SENTENCE LENGTH) 
TABLE 3: Vocational-Technical Models on Survival in Months (Cox regression coefficients, standardized errors in parentheses)

\begin{tabular}{|c|c|c|c|c|c|c|c|c|c|c|c|c|}
\hline \multirow[b]{2}{*}{ Variable } & \multicolumn{3}{|c|}{ Model 1} & \multicolumn{3}{|c|}{ Model 2} & \multicolumn{3}{|c|}{ Model 3} & \multicolumn{3}{|c|}{ Model 4} \\
\hline & \multicolumn{2}{|c|}{$\begin{array}{l}\text { Regression } \\
\text { Coefficient }\end{array}$} & \multirow[t]{2}{*}{$\begin{array}{l}\text { Odds } \\
\text { Ratio }\end{array}$} & \multicolumn{2}{|c|}{$\begin{array}{l}\text { Regression } \\
\text { Coefficient }\end{array}$} & \multirow[t]{2}{*}{$\begin{array}{l}\text { Odds } \\
\text { Ratio }\end{array}$} & \multicolumn{2}{|c|}{$\begin{array}{l}\text { Regression } \\
\text { Coefficient }\end{array}$} & \multirow[t]{2}{*}{$\begin{array}{l}\text { Odds } \\
\text { Ratio }\end{array}$} & \multicolumn{2}{|c|}{$\begin{array}{l}\text { Regression } \\
\text { Coefficient }\end{array}$} & \multirow[t]{2}{*}{$\begin{array}{l}\text { Odds } \\
\text { Ratio }\end{array}$} \\
\hline Demographic variables & & & & & & & & & & & & \\
\hline Age & $-0.033^{\star \star *}$ & $(0.002)$ & 0.967 & $-0.033^{\star * \star}$ & $(0.002)$ & 0.967 & $-0.033^{* \star *}$ & $(0.002)$ & 0.967 & $-0.033^{\star \star *}$ & $(0.002)$ & 0.967 \\
\hline Race & $-0.514^{\star * *}$ & $(0.031)$ & 0.598 & $-0.51^{\star * \star}$ & $(0.031)$ & 0.599 & $-0.527^{\star \star \star}$ & $(0.031)$ & 0.591 & $-0.528^{\star * *}$ & $(0.031)$ & 0.590 \\
\hline Marital status & $0.279^{\star \star *}$ & $(0.033)$ & 1.322 & $0.275^{\star \star \star}$ & $(0.033)$ & 1.316 & $0.293^{* * *}$ & $(0.033)$ & 1.341 & $0.293^{\star \star *}$ & $(0.033)$ & 1.340 \\
\hline \multicolumn{13}{|l|}{ Offense variables } \\
\hline Possession & -0.002 & $(0.059)$ & 0.998 & -0.004 & $(0.059)$ & 0.996 & -0.023 & $(0.059)$ & 0.977 & -0.025 & $(0.059)$ & 0.976 \\
\hline Distribution & $0.324^{* * *}$ & $(0.054)$ & 1.383 & $0.320^{\star \star *}$ & $(0.054)$ & 1.378 & $0.311^{* * *}$ & (0.054) & 1.365 & 0.311 & $(0.054)$ & 1.365 \\
\hline Sentence length & $0.001^{*}$ & $(0.000)$ & 1.001 & $0.001^{*}$ & $(0.000)$ & 1.001 & 0.001 & $(0.000)$ & 1.001 & 0.001 & $(0.000)$ & 1.001 \\
\hline \multicolumn{13}{|l|}{ Independent variables } \\
\hline Vocational-Technical & \multicolumn{2}{|c|}{ - } & - & $-0.228^{\star \star \star}$ & $(0.055)$ & 0.796 & $-0.219^{\star \star \star}$ & $(0.055)$ & 0.803 & $-0.561^{\star \star}$ & $(0.191)$ & 0.571 \\
\hline $\begin{array}{l}\text { Sex } \\
\text { Vocational- }\end{array}$ & \multicolumn{2}{|c|}{-} & - & \multicolumn{2}{|l|}{-} & - & $0.292^{\star \star \star}$ & $(0.055)$ & 1.339 & -0.045 & $(0.191)$ & 0.950 \\
\hline Technical $\times$ Sex & \multicolumn{2}{|c|}{-} & - & \multicolumn{2}{|l|}{ - } & - & \multicolumn{2}{|c|}{ - } & - & 0.369 & $(0.199)$ & 1.446 \\
\hline
\end{tabular}

${ }^{*} p \leq .05 .{ }^{* *} p \leq .01 .{ }^{* * *} p \leq .001$. 
was barely statistically significant. The $-2 \log$ likelihood for this model is $78,925.55$.

In Model 2 of Table 3, we added the independent variable VO-TECH. The control variables maintained the same relationships and significance as in Model 1. Whereas the $-2 \log$ likelihood for Model 2 indicates that more variance is explained, the relationship of VO-TECH with survival time is negative $(b=-0.228, p \leq .001)$, indicating that those who completed vocational education programs had shorter survival times on average than those who did not complete programs. The $-2 \log$ likelihood for Model 2 is 78,909.47.

In Model 3 of Table 3, the independent variable sex (SEX) was added. Analysis indicates that women on average had longer survival times than did men $(b=0.292, p \leq .001)$. The relationships with the control variables remained similar, with the exception that sentence length (SENTENCE LENGTH) was no longer significant. The $-2 \log$ likelihood for this model is $78,878.75$, explaining more of the variance with the addition of the sex variable. Figure 2 graphically depicts these findings.

In Model 4, we tested for interaction between the two independent variables $(\mathrm{VO}-\mathrm{TECH} \times \mathrm{SEX})$. The interaction was not statistically significant at the $\alpha=.05$ level. However, the coefficient approached statistical significance $(p=.06)$.

\section{DISCUSSION}

Before turning to a discussion about the relationship between correctional education and recidivism rates in Oklahoma, a brief discussion of the control variables is needed. Most of the relationships were as expected, although some were surprising. Older offenders were more likely to return to prison in a shorter period of time. This may be due to repeat incarcerations. In this study, we did not examine the effect of prior incarcerations. However, it is worth noting that other research has found higher recidivism rates among younger offenders (Harer, 1995).

We also found that Black offenders had shorter survival times, even controlling for offense type, sentence length, and the demographic variables (Harer, 1995). However, our findings that single offenders fared better than did married offenders was somewhat surprising and in contradiction with other research. Harer reported that being married was associated with lower recidivism rates. However, his study focused on marital status at the time of release, whereas our data reflect marital status at time of incarceration. It may be that many who show as "married" in our sample subsequently became divorced. The loss of marriage is one possible explanation for our results. 


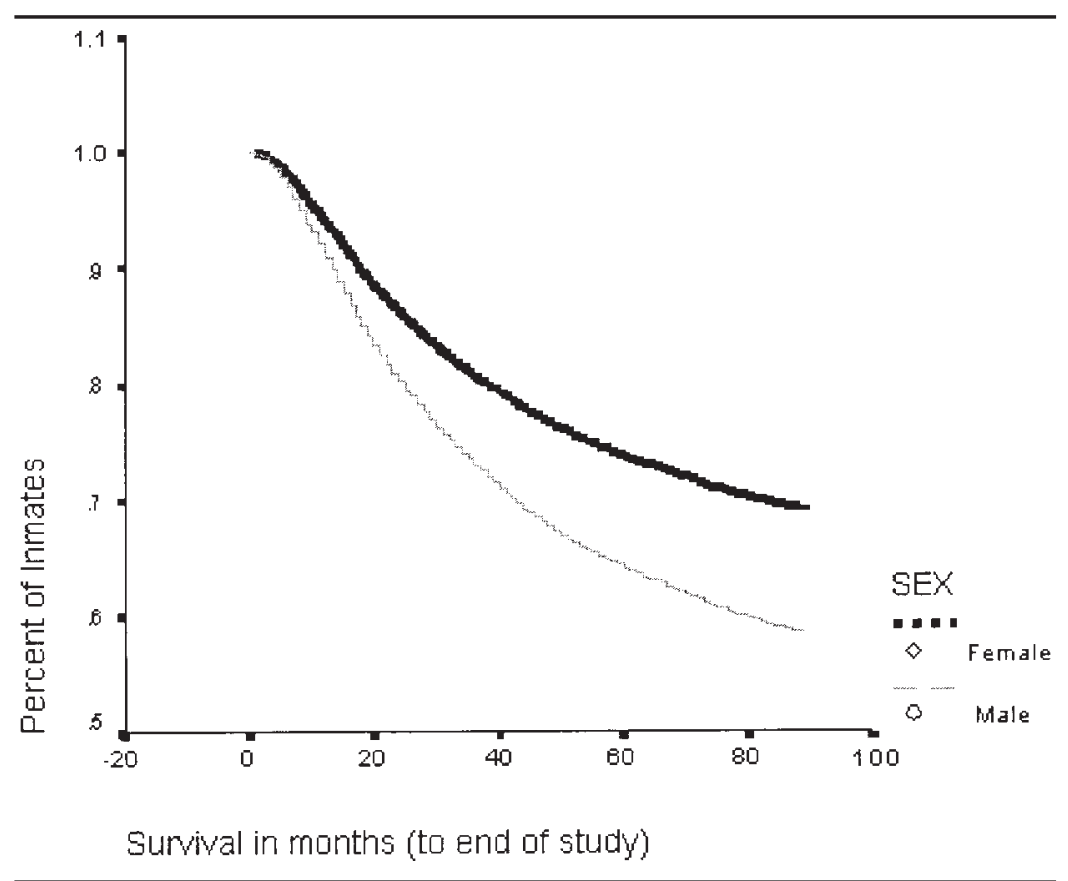

FIGURE 2: Survival in Months by Oklahoma Department of Corrections (vocationaltechnical model)

Finally, our findings concerning the effects of drug charges were interesting. Unlike prior research (Harer, 1995), we found that having a conviction for illegal possession of a controlled substance had no relationship with survival time for this population. In other words, those convicted of possession charges were not qualitatively different from non-drug offenders in terms of staying out of prison upon release. However, a conviction for illegal distribution was associated with more favorable outcomes. Those prisoners incarcerated for drug distribution fared better, staying out of prison longer than the average prisoner. There could be a number of reasons for this. One that has potential merit is that many of those convicted of drug distribution may have resorted to drug sales due to a lack of education and/or job skills. Once given the opportunity to improve their situations, they may have chosen more legitimate avenues of earning.

The results of this study mirror earlier studies, indicating there are no easy answers about the effectiveness of educational programs in reducing recidivism. Our findings are consistent with other research, indicating that GED 
program completion provides a greater chance of survival for both male and female offenders (Beck \& Shipley, 1989; Flanagan, 1994; Harer, 1994; Jancic, 1998). However, current vocational programs in Oklahoma appear to be ineffective or even harmful in some situations. Furthermore, this is not a new finding for Oklahoma corrections (Brewster, 1999; Chown \& Davis, 1986; Davis, 1985). Research has consistently suggested that inmates in Oklahoma who complete vocational training return to prison in a shorter period of time than those who do not complete vocational-technical training. It is, however, important to note a shortcoming in our analyses. The data do not allow us to address offenders who are reincarcerated in another state and they do not address inmates who are deceased (Jancic, 1998).

Turning to the analyses of the efficacy of GED programs, the results suggest that inmates benefit from completion of a GED program while incarcerated. This may be particularly salient for women. A majority of female offenders have children and, due to pregnancy, some have dropped out of high school to meet their children's needs-both financial and social. Those who use their prison experience to their benefit by getting a GED also provide themselves with the needed tools to stay out of prison. Men who receive a GED also benefit from the program. Those receiving the equivalent of a high school diploma are raised to a more equal footing with other high school graduates and are better able to stay out of prison for longer periods of time. These results would suggest that policy makers and prison administrators should place greater emphasis on offenders obtaining a GED while incarcerated.

The results of the vocational-technical analyses are more troubling and must be viewed with extreme caution. Our findings suggest the Oklahoma vocational-technical programs are at best ineffective in improving the chances of survival. Indeed, they suggest that completion of a vocationaltechnical program may actually be detrimental in the efforts to reduce recidivism, supporting earlier findings (Brewster, 1999; Chown \& Davis, 1986; Davis, 1985). However, interpretation of these findings is no easy task. This study looks at the effects of the vocational-technical programs overall, not the characteristics of individual programs. Thus, it is important to assert that this study does not condemn the use of vocational education programs in general. However, it does indicate that the system currently under use in Oklahoma needs thorough examination. Indeed, it points to the need to assess which programs may be more effective in reducing recidivism, for whom, and under what conditions.

There are a number of possible explanations for our findings. First, there is a degree of self-selection into vocational programs (Martinson, 1974; D. B. Wilson et al., 2000). Self-selection into a program can occur for a number of 
reasons. It may be viewed by the inmate as a route to improving the likelihood of parole, or it may be viewed as a way to retain privileges. In Oklahoma, self-selection into vocational education is directed by Department of Corrections guidelines. Inmates are assessed for need and then referred for possible vocational-technical training. For many inmates, vocationaltechnical completion is a condition for parole (Oklahoma Department of Corrections, 2001). Thus, many of those participating in the programs may be disinterested in improving their skills and more interested in retaining privileges or obtaining parole (Martinson, 1974). Furthermore, we did not have information regarding which inmates were assessed as needing training. Therefore, it may be that those who "need" vocational training are more likely to recidivate due to other characteristics, regardless of program completion. Unfortunately, the data did not allow us to explore this more fully.

Another explanation also merits further investigation. The current practice of frequently moving inmates to different facilities may also contribute to our findings. Because our vocational-technical measure is actually a measure of program completion, it may be that offenders with longer survival times were also program participants but lacked the opportunity to complete their chosen courses. It would be fruitful to examine the histories of inmates who began but did not complete vocational-technical programs. However, Department of Corrections data do not incorporate these data. Examination of each individual file would be necessary to obtain this information. Therefore, we acknowledge that limitation as well as our inability at this time to explore the relationship between recidivism rates and enrollment in vocational-technical programs without completion. Furthermore, we believe that completion may be a more accurate assessment. In an era of credentialization, participation in a vocational-technical program without completion might provide skills but would not provide offenders with the necessary credentials to obtain employment.

The timing factor is also an important aspect of recidivism reduction (Harr, 1999). If education occurs too far in advance of release, the inmate may lose the motivation to change that might have occurred during the education process. The normalization argument suggests that successful rehabilitation consists of replacement of "criminal" norms with mainstream norms (Allison, 1993; Foucault, 1977/1995; Harer, 1995; Harr, 1999). The normalization hypothesis would suggest that recidivism occurs because rehabilitation efforts fail to ensure changes that will remain after release (Allison, 1993). When the "rehabilitation process" is not quickly followed by release, the resocialization may be lost, and the inmate may adopt prison norms (Harr, 1999). In Oklahoma, the policy is to place inmates within 18 months of discharge into programs unless they have a vocational parole stipulation 
(Oklahoma Department of Corrections, 2001). However, there is a caveat to this: Those offenders whose parole stipulates vocational training may be placed in a program when a slot is available. Unfortunately, we were not able to determine the relationship between the program completion date and the discharge date.

The more rapid recidivism of vocational-technical program completers may also be due to the effects of rising expectations that are ultimately unmet (Brewster, 1999). If offenders are told that the program will benefit them, it would be natural for the offenders to have raised expectations about the possibility of employment after release. If upon release, the offenders cannot find jobs in their areas of training, it could leave them disillusioned and feeling even more trapped in the system. This in turn could increase the likelihood of a return to crime. With the lure of "big" money in the illegal drug economy, disillusioned offenders may turn to selling drugs instead of using their newly acquired skills. Or, they may simply turn to drug use as a coping mechanism for the stress of trying to support themselves and a family. The problem of high expectations is further exacerbated by the lack of assistance in obtaining jobs. Prior research has indicated that an important correlate of postrelease success is job placement (Harer, 1995). Indeed, research indicates that obtaining a postrelease job prior to leaving prison significantly lowers recidivism (Harer, 1995). In Oklahoma, inmates receive no assistance from the Department of Corrections in finding job placement. Thus, inmates leaving prison may become discouraged and eventually adopt a "why bother" attitude.

Regardless of the explanation, it is clear that the state of Oklahoma should investigate its current educational programming. The success rates of different types of vocational programs need to be determined. Furthermore, for vocational-technical programs to be successful, jobs must be available for those completing the programs. Administrators must ensure that those offenders who complete either the GED or vocational-technical programs are placed in jobs that are not merely minimum wage positions. Without sufficient confidence of survival as productive members of society, the dangers

of a past life of crime will be forgotten by offenders, leading to a return to crime.

\section{POLICY IMPLICATIONS AND DIRECTIONS FOR FUTURE RESEARCH}

Program completion by Oklahoma prisoners is low. Only $18.2 \%$ of eligible offenders had completed the GED program. This must be addressed for 
both the offenders' and society's sake. This study adds to the large amount of research demonstrating the benefits of obtaining a GED while incarcerated. The benefits of the GED program thus need to be provided to offenders without high school completion, who in turn need to be encouraged to participate. In particular, young women who enter the department without a high school diploma should be made aware of the benefits of the GED program.

This study also raises questions about the vocational-technical programs in the Oklahoma Department of Corrections. It will be important for future research to assess "what works and for whom" (Duguid et al., 1996). Future analyses should concentrate on linking recidivism rates to specific programs. In addition, there is a need to determine which offenders fare better in which programs.

Women's vocational-technical programs in the Oklahoma Department of Corrections include programs such as horticulture and basic computer skills (Brewster, 1999). The question for policy makers is, then, do these programs provide women with marketable skills in the Oklahoma economy? Horticultural work is often seasonal, with low pay at entry positions. Do horticultural skills provide a viable way to support a family? Men's vocational-technical programs also appear to be hurting Oklahoma offenders. The same questions about the programs — in terms of marketability and need — must be answered for men.

Program participation may be an indication of offenders' understanding of the problem. Less than $7 \%$ of those eligible for vocational-technical programs have participated in and completed the programs. This may be a positive finding for offenders because the program in its current state has been found to lower survival times.

Further research is also needed to explore specific differences in vocational-technical programs, including gender differences. When looking at only those who participated in vocational-technical programs, do the survival times for men and women differ in systematic ways? Answers to these questions should provide policy makers better insight to the specific benefits and deficits of both programs. Indeed, this study suggests the need to follow the suggestions of Duguid and colleagues (1996) in assessing what programs work in what sets of circumstances.

\section{NOTES}

1. Six cases in the GED subsample and 13 cases in the total sample were dropped from analyses due to error in the reporting of survival time, resulting in final sample sizes of 5,746 for the GED analyses and 11,800 for the vocational-technical analyses. 


\section{THE PRISON JOURNAL / September 2002}

2. The latest date participants were released was December 31, 1994, and recidivism was tracked through July 1997. Thus, our measure of recidivism tracks offenders 2 and a half years postrelease. Prior research indicates that the rate of recidivism is far higher in the first year postrelease and drops almost 50\% in the second year and again in the third year (Harer, 1995).

3. The Oklahoma Department of Corrections does not provide data on common-law marriages.

4. In Oklahoma, African Americans account for approximately $7 \%$ of the total population, far below the national percentage of Blacks.

5. The recidivism rate is consistent with the findings of earlier studies of Oklahoma offenders (Chown \& Davis, 1986; Holley \& Brewster, 1997).

6. We tested for an interaction between GED and sex. The interaction term was not statistically significant.

7. We tested for an interaction effect between GED and sex. The interaction term was not significant.

\section{REFERENCES}

Allison, T. L. (1993). Making offenders more accountable and offering opportunity for change. Corrections Today, 55, 92-106.

Anderson, D. B., Schumacher, R. E., \& Anderson, S. L. (1991). Releasee characteristics and parole success. Journal of Offender Rehabilitation, 17, 133-145.

Andrews, D. A., Zinger, I., Hoge, R. D., Bonta, J., Gendreau, P., \& Cullen, F. T. (1990). Does correctional treatment work? Criminology, 48, 406-413.

Babbie, E. (1995). The practice of social research (7th ed.). Belmont, CA: Wadsworth.

Batiuk, M. E., Moke, P., \& Roundtree, P. W. (1997). Crime and rehabilitation: Correctional education as an agent of change-A research note. Justice Quarterly, 14, 167-180.

Beck, A. J., \& Mumola, C. J. (1998). Prisoners in 1998. Washington, DC: Bureau of Justice Statistics.

Beck, A. J., \& Shipley, B. E. (1989). Recidivism of prisoners released in 1983. Washington, DC: National Institute of Justice.

Brewster, D. (1999). GED and Vo-Tech: Does rehabilitative justice decrease recidivism for the women of the Oklahoma Department of Corrections? Unpublished master's thesis, University of Oklahoma, Norman.

Carlson, J. R. (1995). Usefulness of educational, behavior modification, and vocational programs as perceived by female inmates. Journal of Offender Rehabilitation, 22, 65-76.

Chown, B., \& Davis, S. (1986). Recidivism among offenders incarcerated by the Oklahoma Department of Corrections: A survival data analysis of offenders released January 1982 through July 1986 and case-control study of offenders received in 1985 and 1986. Oklahoma City: Oklahoma Department of Corrections.

Council of State Governments, Center on Crime, Communities and Culture. (1998). Education as crime prevention: Providing education to prisoners. Spectrum, 71, 26-28.

Davis, S. P. (1985). Recidivism among offenders released from incarceration in 1982. Oklahoma City: Oklahoma Department of Corrections.

Duguid, S., Hawkey, C., \& Pawson, R. (1996). Using recidivism to evaluate effectiveness in prison education programs. Journal of Correctional Education, 47, 74-85.

Flanagan, T. J. (1994). Prison education research project final report. Huntsville: Sam Houston State University Criminal Justice Center. 
Brewster, Sharp / EDUCATIONAL PROGRAMS AND RECIDIVISM 333

Foucault, M. (1995). Discipline and punish: The birth of the prison. New York: Random House/ Vintage Books. (Original work published 1977)

Gerber, J., \& Fritsch, E. J. (1995). Adult academic and vocational correctional education programs: A review of recent research. Journal of Offender Rehabilitation, 22, 199-242.

Glaser, D. (1966). The effectiveness of correctional education. American Journal of Correction, 28, 351-363.

Harer, M. D. (1994). Recidivism among federal prison releasees in 1987: A preliminary report. Unpublished report to the Federal Bureau of Prisons, Washington, DC.

Harer, M. D. (1995). Recidivism among federal prisoners released in 1987. Journal of Correctional Education, 46(3), 98-128.

Harley, D. A. (1996). Vocational rehabilitation services for an offender population. Journal of Rehabilitation, 62, 45-50.

Harr, D. (1999). A plea from behind bars: Take a chance on education. Social Policy, 30, 50.

Henry, G. T. (1998). Practical sampling. In L. Bickman \& D. J. Rog (Eds.), Handbook of applied social research methods (pp. 101-126). Thousand Oaks, CA: Sage.

Holley, P., \& Brewster, D. (1997). An examination of the effectiveness of GED programs within the Oklahoma Department of Corrections. Manuscript submitted for publication.

Jancic, M. (1998). Does correctional education have an effect on recidivism? Journal of Correctional Education, 49(4), 152-161.

Kernodle, J. R., Joyce, C. C., \& Farmer, R. J. (1995). Changing the behavior of DWI firstoffenders. Journal of Offender Rehabilitation, 22, 113-128.

Lab, S. P., \& Whitehead, J. T. (1990). From "nothing works" to "the appropriate works." Criminology, $48,406-413$.

Martinson, R. (1974). What works? Questions and answers about prison reform. Public Interest, $35,22-54$.

Martinson, R. (1979). New findings, new views: A note of caution regarding sentencing reform. Hofstra Law Review, 7, 243-258.

McCollum, S. (1977). What works: A look at effective correctional education and training experiences. Federal Probation, 41, 32.

Morash, M., Haarr, R. N., \& Rucker, L. (1994). A comparison of programming for women and men in the U.S. prisons in the 1980s. Crime \& Delinquency, 40, 197-221.

Morison, K. P. (1992). Reading, writing \& recidivism. Council of State Governments, 35(11), $10-11$.

Oklahoma Department of Career and Technology Education. (2001). Available from http:// www.okcareertech.org

Oklahoma Department of Corrections. (1998). Inmate profile for end of month population for June 1998. Retrieved May 7, 2001, from http://www.doc.state.ok.us/Profiles/pop0698.htm

Oklahoma Department of Corrections. (1999). Female offender task force work summary, fiscal year 1999. Oklahoma City: Author.

Oklahoma Department of Corrections. (2001). Policies and procedures, Section 09: ProgramsCareer tech technical training. Retrieved May 7, 2001, from http://:www.doc.state.ok.us/ offtech/op090133.htm

Piehl, A. M. (1998). Economic conditions, work, and crime. In M. Tonry (Ed.), The handbook of crime and punishment (pp. 302-319). New York: Oxford University Press.

Ryan, T. A., \& Mauldin, B. J. (1992). Correctional education and recidivism: An historical analysis. Columbia, SC.

Schnur, A. (1948). The educational treatment of prisoners and recidivism. American Journal of Sociology, 54 . 


\section{THE PRISON JOURNAL / September 2002}

Schram, P. J. (1998). Stereotypes about vocation programming for female inmates. The Prison Journal, 78, 244-270.

Schumacher, R., Anderson, D., \& Anderson, L. (1990). Vocational and academic indicators of parole success. Journal of Correctional Education, 41, 8-13.

Sims, B., \& Jones, M. (1997). Predicting success or failure on probation: Factors associated with felony probation outcomes. Crime \& Delinquency, 43, 312-327.

Snell, T., \& Morton, D. (1994). Bureau of Justice Statistics special report: Women in prison. Washington, DC: Office of Justice Programs.

Stevens, D. J., \& Ward, C. S. (1997). College education and recidivism: Educating criminals is meritorious. Journal of Correctional Education, 48(3), 106-111.

Tracy, A., Smith, L. G., \& Steurer, S. (1998). Standing up for education: New CEA study seeks to definitively show correlation between education and reduced recidivism. Corrections Today, 60, 144-147.

Weisheit, R. (1985). Trends in programs for female offenders: The use of private agencies as service providers. International Journal of Offender Theorapy and Comparative Criminology, $29,35-42$.

Wilson, D. B., Gallagher, C. A., \& MacKenzie, D. L. (2000). A meta-analysis of correctionsbased education, vocation and work programs for adult offenders. Journal of Research in Crime \& Delinquency, 37, 347-368.

Wilson, P. R. (1994). Recidivism and vocational education. Journal of Correctional Education, $45,158-163$.

Winifred, M. (1996). Vocational and technical training programs for women in prison. Corrections Today, 58, 168-171. 